\title{
Editorial Journal-First Publication for the Software Engineering Community
}

IEEE Transactions on Software Engineering (TSE) and ACM Transactions on Software Engineering and Methodology (TOSEM) are jointly initiating a uniform approach to "journal-first" publication for the software-engineering research community. The goal is to provide a mechanism whereby research results that may be a better fit for publication via the journal review process can be broadly disseminated to the community through presentation in the technical research tracks of ACM- and IEEE-sponsored conferences. As in other communities that provide a journal-first publication route (such as the VLDB conference in the database community), authors choosing this route benefit from the absence of page limits and annual submission deadlines and the possibility of having their submissions undergo multiple rounds of review and revision.

TSE and TOSEM are now considering manuscripts for review in a new submission category called "Journal-First" that can be selected in Manuscript Central at the time of submission.

Authors of journal-first manuscripts will be required to declare that their paper qualifies for publication and presentation via the journal-first process. In short, journal-first manuscripts report research contributions that have not already been presented in prior publications. Papers that extend prior publications (particularly conference papers) by providing, for example, additional detail (proofs, algorithms, etc.) or expanded empirical evaluation that further supports the contributions of the prior publication would not qualify as journal-first. Papers that report completely new contributions or that build on prior work in substantial ways that lead to distinct and novel contributions beyond the prior work would qualify as journal-first. Ultimately, the community of reviewers and editors charged with assessing a submitted manuscript will judge whether a paper is sufficiently novel in its contributions to be considered journal-first; papers that do not qualify may be shifted to existing manuscript categories in TSE or TOSEM, and the authors will be so notified.

Journal-first submissions to TSE and TOSEM will be reviewed using the same rigorous review process already in place for current submission categories and in the same timely manner that the journals strive to maintain. Once a journal-first manuscript is accepted, it will be made available to organizers of upcoming software engineering conferences so that it can be included in a conference technical research track. TSE and TOSEM will actively promote all accepted journal-first papers for inclusion in conference programs for two years after their publication date.

Conference organization is independent of TSE and TOSEM, so it is not possible to require a conference to include an accepted journal-first manuscript, nor is it possible to require an author of a journal-first manuscript to accept an invitation to present their work at a conference. Despite the lack of guarantee, this model of presenting a pool of novel technical contributions to conference organizers has already proven effective. The editorial boards of TSE and TOSEM identified a set of papers that fit

Permission to make digital or hard copies of part or all of this work for personal or classroom use is granted without fee provided that copies are not made or distributed for profit or commercial advantage and that copies bear this notice and the full citation on the first page. Copyrights for third-party components of this work must be honored. For all other uses, contact the Owner/Author.

2015 Copyright held by the author/owner(s).

1049-331X/2015/11-ART1

DOI: http://dx.doi.org/10.1145/2837717 
the journal-first criteria and made those available to the organizers of ICSE 2015 and ESEC/FSE 2015. As a result, the authors of seven of those papers have enjoyed the opportunity to present their work at those conferences.

Our hope is that creating an official journal-first manuscript category for TSE and TOSEM will both expand the number and quality of papers available to conference organizers and provide authors with a useful additional outlet for presenting their research. This will, in turn, help conference organizers appreciate the value of this new source of scientific content for their meetings and, ultimately, to establish long-term journal/conference relationships that provide ample outlet for journal-first research results.

This journal-first initiative is a first step in maturing the software engineering publication ecosystem to one that can accommodate a richer variety of contributions and presentations, while providing all those contributions the opportunity for broad community dissemination at conferences and providing authors all the networking and reputation-building benefits that come from conference participation.

Matthew B. Dwyer

Editor-in-Chief

IEEE TSE

David S. Rosenblum

Editor-in-Chief

ACM TOSEM 